\title{
COMPONENTS OF A POLITICAL ENERGETIC SUSTENTABLE: TRADE OF RIGHTS OF EMISSION OF GREENHOUSE GASES (Board 2003/87/CE), INTERNATIONAL MECHANISMS BASED ON PROJECTS and FUNDS OF CARBON
}

\author{
Redondo Gil, C. ; Alonso, A.M.; Esquibel L.A. y Zapico, P. \\ ${ }^{1}$ Professor of University School of Electrical Engineering. \\ Department of Electrical and Electronic engineering. \\ Industrial and Computer school of Engineerings. University of León. 24071-León (Spain). \\ Phone.:+34987291786 diecrg@unileon.es
}

\begin{abstract}
.
Macroeconomic evaluation from the perspective of parameters of Economy of the Public Sector of the effect on the environment of effect gases conservatory and the definition of technological and financial tools that guarantee efficient levels of control.

Revision of the general criteria that must as much govern the regulating actions of the National Plans of allocation of Rights of Emission as in the design of flexible programs of promotion of technological projects of Joint Application between signatory countries of the Protocol of Kyoto as Mechanism for a Clean Development in other people's countries
\end{abstract}

Definition of management tools, exchangeable credits of emission in the communitarian market.

Joint of financial instruments that canalize programs of collective investment in technological projects, Funds of Carbon, that reduce the costs of information, communication transaction and implementation with a consequent reduction of the risks.

Consideration of the necessity simultaneously to conjugate and to put in practice state reference instruments of the external economies associated to the productive processes of the power sector that consider social aspects, programs of economic reactivation and the fulfilment of commitments in the matter of climatic change and prevention of contamination.

\section{Key words}

Political Energetic and of Environmental Management. Sustainable development. Commerce of Rights of Emission (CRE). Projects of Joint Application (AC). Mechanism for a Clean Development (MCD).

\section{Political Energetic and of Environmental Management.}

The model of development of the producing companies of energy in the current international frame, answers to the stereotype of an external economy of production of technological character. The producing agent can be compensated by the benefits of the producing activity and not necessarily one sees obliged to assume the totality of the associate costs. It is necessary to determine, to define, to quantify and to shape the benefits and external costs, the effects pollutants against the environment, the instruments and the efficient level of the pollution control of the environment inside what they constitute political and national and supranational measurements.

The measurements and strategies of national character can and must go accompanied of the staging of new mechanisms and technological and financial hardware that they contribute to the development of political joint and balanced of local and international character that there facilitate the attainment of the targets proposed and assumed with the signature of the Protocol of Reduction and Limitation of Gas Emission of Hothouse effect and the diffusion of new technologies of energy production, in particular from more innocuous renewable sources of energy with the environment. The putting in practice of political these promises to turn into an effective formula for the innovation and transference of technology and the sustainable development of new energy forms.

The most direct mechanism of market and effective to correct the distortions of the energy market would be initially of burdening fiscally the production of electricity from conventional sources up to the level of the costs outsourcing for every technology. In this sense and in spite of a few fearful advances the opposition and geopolitical resistance and macroeconomics provoked by the reform of energy tax system generate and suppose a few barriers of entry that postulate them difficult to raise. For this reason there have appeared in the last decade in the western sphere compensatory solutions that are faced to encourage with alternative formulae the renewable energies, which they constitute undoubtedly an 
opportunity of future for the same ones. The Protocol of Kyoto foresees the use of international mechanisms of market based on criteria economic that try to help the states to fulfil of efficient form the targets of reduction and/or limitation of emissions.

Political and National Measurements must be complemented and brought together with the participation in the systems of commerce of rights of emission and with the development of technological projects in Joint Application between countries integrated to the Protocol of Kyoto and by means of projects based on the Mechanism for a Clean Development of countries foreign to the protocol.

A country of reference in the design of multilateral programs of performance is Holland that has designed a Strategic Plan that postulates to reduce six per cent of his emission in 1990 in the period 2008-2012 combining Political Nationals; Projects of transference of clean technologies to countries less developed in the field of South America and Asia (Bolivia, Brazil, China, Costa Rica, El Salvador, India, Indonesia, Jamaica and Panama); Projects of Joint Application in the Centre and East of Europe and promoting the commerce of rights of emission and taking part, across Prototype Carbon Fund and Community Development Carbon Fund, in the Funds of Carbon.

\section{Contamination of the environment and the efficient level of control.}

The Graph 1 represents the typical situation of a productive activity that bears external productive economies of technological character of negative type. In it represents the existence of a marginal cost deprived for the producing agent of energy that it does that from a level $\mathrm{Q}_{0}$ of production a by-product (contamination) is generated and that implies an additional increasing cost as there increases the level of production, cost associated with the productive process not supported by the producing company that it does that the Social cost every time moves away more of the function of Private cost.

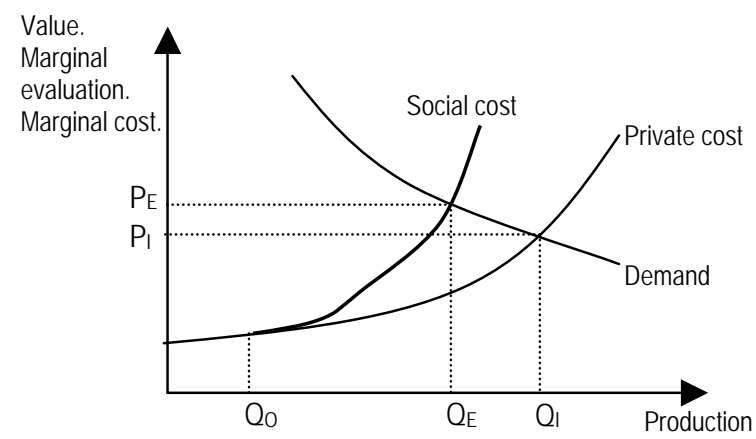

Graph 1. Relation value / marginal cost vs. Production

The free functioning of the market tends to a breakeven $\mathrm{Q}_{\text {। }}$ in which the marginal evaluation that the claimants of energy give is lower than the marginal cost which one incurs from a social global perspective. The level of production $Q_{\text {। }}$ is a level superior to the efficient level of energy production $\mathrm{Q}_{\mathrm{E}}$ in which the marginal evaluation is equal to the social cost of the productive process of energy.

The existence of external productive technological proper economies of character of the energy sector they do that the markets do not obtain an efficient allocation of resources making to him necessary the intervention of the states and the design, development and implementation of hardware and instruments of control and, in his case, a combination of the same ones.

Marginal evaluation of the quality of the Environment. Marginal cost of reducing the contamination.

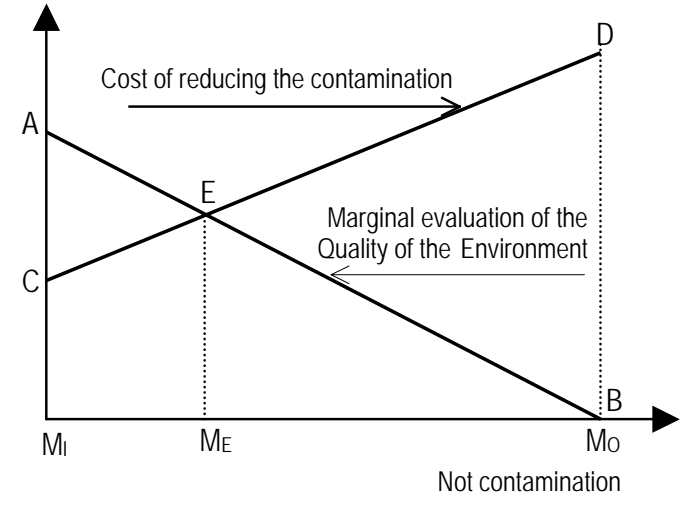

Quality of the Environment

Graph 2. Marginal evaluation of the quality of the environment / marginal cost of reducing the contamination vs. Quality of the environment.

Departing from the premise of considering the quality of the environment to be the production of a good (Graph 2, Abscissas, quality levels of the environment of increasing character of left side to right hand; arranged, marginal evaluation of the different levels of quality of the environment and marginal cost of reducing the contamination) it is necessary to establish following considerations: for very high levels of contamination $M_{1}$ evaluation granted to the control of the contamination is very high. On the contrary as it improves the quality of the environment the marginal evaluation diminishes becoming a zero in absence of contamination.

The quality of life obtained as consequence of an independent, proper performance of the free functioning of the market, he would be $M_{1}$ correspondent at a level of production $\mathrm{Q}_{\mathrm{l}}$, level in which the difference is not born by no means in mind between costs social and deprived of energy production. $\mathrm{M}_{0}$ supposes a high index of quality of the environment in it is possible to be considered that contamination does not exist, in mail at a level of production $\mathrm{Q}_{0}$ characterized by the absence of social costs.

Finally the point $M_{E}$, who corresponds at the level of production $\mathrm{Q}_{\mathrm{E}}$, represents the breakeven where the marginal value of control of the environment coincides with the marginal cost of reducing the contamination and that can be considered to be the efficient level of quality of the way or the efficient level of control of the 
contamination that eliminates proper levels of difference of other levels of environmental quality.

It is necessary to conclude in this point that the marginal cost of reducing the contamination is the value of the goods and services from which it is necessary to resign to increase the measurements of control of the contamination or, from another point of view, the value of the goods and services from which it is necessary to resign if one wants to support certain levels of quality of the environment.

\section{Instruments of state control of the contamination of the Environment.}

Essentially four feasible instruments can be established of being used by the State as mechanisms of control of the environmental contamination:

a) The awarding of rights of property on the Environment, cash in case of external economies that affect a limited number of agents and where the State is capable of defining exactly the rights of property.

b) Establishment of taxes on the activities or substances pollutants or a direct tax on the contamination itself. This instrument manages to reduce the level of activity that originates the contamination but, in yes same, does not establish any incentive to design and to implement alternative technologies. The principal disadvantage centres on establishing the exact quantity of the tax to applying.

c) Public subsidies. This instrument assigns the rights of property of the environment whom they contaminate and it loads the costs of control of the contamination on the taxpayers. This system does not offer monetary incentives so that the level of contamination diminishes in the sources

d) Commerce of rights of emission. The State fixes the standard level of contamination and controls directly the level of degradation of the environment. These standards can apply to themselves alternative or simultaneously to the emission of substances pollutants or to the quality of the environment. The cost of expiring with the regulation relapses in general on the producers and direct consumers of the goods. The system complements itself with the creation and selling on part of the state of permissions of contamination. The states fix previously a certain level of degradation of the way expressing simultaneously a certain number of rights of emission that are extracted to public auction, the buyers will be ready to pay until the price turns out to be similar to the costs associated with the control of the contamination.

A coherent combination of this tools, which happens for one reasonable and acceptable commitment of reduction of the emission of hothouse, will allow to design strategic geopolitical and technological plans based in economic notion and come up environmental commonly recognized and compromised with the revitalization of a sustainable development
In the strategic model proposed by the Spanish state ${ }^{1}$ there is claimed to agree on the joint of protocols of commerce of rights of emission (deals are foreseen by value for 200 million euros for the exercise 2005) ${ }^{2}$ with the maintenance of subsidies, 60 cents by $\mathrm{KW}^{3}$, destined to encourage the use of national coal in the thermal power-station ${ }^{4}$.

\section{International mechanisms of support to the fulfilment of the guidelines of the Protocol of Kyoto.}

\section{A. Commerce of Rights of Gas emission of greenhouse effect}

The object of the Board 2003/87/CE of the European Parliament and of the Advice of October 13, 2003 is of regulating the commerce of rights of gas emission of hothouse effect inside the European Union in order to foment the reduction of the emission of these gases of an effective and economically efficient form.

A right of emission grants to his holder the right to liberate to the ambience, during a certain period, a metric ton of dioxide of carbon $\left(\mathrm{CO}_{2}\right)$ or a quantity with an equivalent potential of warming of the planet of methane $\left(\mathrm{CH}_{4}\right)$, nitrous oxide $\left(\mathrm{N}_{2} \mathrm{O}\right)$, hidrofluorocarburos (HFC), perfluorocarburos (PFC) or hexafluoruro of sulfur $\left(\mathrm{SF}_{6}\right)$.

The commerce of rights of emission is a mechanism of market that allows to the issuing facilities of gases of hothouse to exchange the rights of emission previously assigned to each of them. The commerce of rights of emission is only possible in the measurement in which beech, on the one hand, facilities which emission of gases of hothouse overcomes the rights of emission assigned and, on the other hand, facilities which emission of hothouse is low to which they would allow the rights of emission assigned.

The latter facilities will be able then, if this way they decide it, to sell the remaining rights of emission to the companies which emission has overcome the initial quota of assigned rights.

This way, meanwhile selling companies of rights of emission will see rewarded economically his effort of reduction of emission, buying companies of rights will avoid to be fined for exceeding his quota assigned of rights.

\footnotetext{
${ }^{1}$ Redondo GIL, C. Y CARBAJo Nogal, C.; Regulatory strategies of the Renewable Energies in the European Union. The Ist Technical congress on Renewable Energies. Chair of the Renewable Energies of the University of León. Departament of Economy and Employment of the Meeting of Castile and León. General direction of Energy and Mines. University of León, November, 2003.

${ }^{2}$ Peter Sweatman, Climate Change Capital (CCC) in Spain. On January 14, 2005

${ }^{3}$ Plan of the Coal 2006-2012. Department of Industry Spain.

${ }^{4}$ REDONDO GIL, C.; Environmental strategies in the mining and energy sectors. Security, Quality and Environment in the Engineering of Mines: Our Future (2003). Department of Economy. General Direction of Energy Politics and Mine. Official Laboratory Madariaga Polytechnical University of Madrid. Univ. Polytechnical of Catalonia. (Barcelona) November, 2003.
} 
The economic logic of the system of commerce of rights of gas emission of hothouse ${ }^{5}$ takes root in that by means of the exchange of rights it is achieved that the necessary reduction of emission to fulfil an environmental predetermined target realizes there where the cost of this reduction is lower.

This mechanism of market allows to obtain this way the same environmental global targets that had been reached to fulfil all the facilities his quotas of emission assigned but with the advantage of which all the companies limit his costs of adequacy to the regulation: some, because they have extra income derived from the selling of rights and others, because there save themselves the costs sanction, public negative image, etc. - that would stem of expressing over the allowed for his rights of emission assigned.

All the economic realized analyses coincide that the starting of the community diet of rights of gas emission of hothouse will allow to reduce considerably the costs of fulfilment of the commitments of reduction of emission. According to the calculations of the European Commission, the cost saving will reach every year as minimum 1.326 million $€$ during the first phase, that is to say, $35 \%$ of the costs that would have to fulfil the commitments without European market of emission. The principal saving will correspond globally to the sector of energy activities (1.084 million $€$, $33 \%$ of his alternative costs of fulfilment), whereas the metallurgical industry of iron minerals will save 209 million $€$, which there supposes $50 \%$ of his alternative costs of fulfilment.

The environmental logic of the system of commerce of rights of emission takes root in the incontestable fact of which the climatic change is an environmental global problem since the emission of hothouse effect has consequences to planetary scale independently of the place where they take place ${ }^{6}$. It is for it, that from an environmental point of view, the place in which the emission diminishes has little importance if real reductions of the same ones are obtained. The creation of a European market of rights of gas emission of hothouse takes as an end to contribute to the fulfilment, of an economically efficient way, of the community targets of reduction of the emission of hothouse. From this perspective, only it has sense, environmentally speaking, to start this market if the entire quantity of rights of emission that will be assigned is coherent with the commitments of reduction.

At first, in the initial period (2005-2007) only rights of emission will be assigned to the facilities and energy activities of combustion with a thermal nominal potency superior to $20 \mathrm{MW}$ - included the plants of cogeneration but with the exception of the facilities of dangerous or municipal residues-, the refineries of hydrocarbons and coque factories.

\footnotetext{
${ }^{5}$ CARMona, CARRasco y FdeZ-Revuelta (1993): " An approach to interdiscipline of the accounting of the environment ". Spanish magazine of Financing and Accounting. Vol. The XXIInd. N ${ }^{\circ}$ 75. April - July. Pp. 277-305

${ }^{6}$ CAPRA (1991): " The new ecological paradigm ". Integral magazine. $\mathrm{N}^{\mathrm{o}}$ 22. Monographic: "Piece of news Makes aware ", Pp. 26-31.
}

The value threshold of $20 \mathrm{MW}$ applicable to the facilities of combustion refers in general to the production capacity of the plant to the effect that if the same holder will realize several activities of the same category in the same installation or emplacement, the capacities of the above mentioned activities would join.

The entire exclusion of the facilities of incineration of residues of the ambience of application of the Board justifies itself, according to the European Commission, for the difficulties of measuring the content of carbon of the burned residues.

Among the consequences derived from the participation of the energy sector in the commerce of rights of emission it is necessary to emphasize that although the starting of the community diet of commerce of rights of gas emission of hothouse will allow to the energy sector of the EU to reduce at least $33 \%$ the costs that it had had in case of having to expire with not marketable quota of emission, the cost for the energy sector of the EU of his participation in the commerce of emission thinks that it will reach, according to the European Commission, a maximum of 2.200 million annual $€$. This quantity will be destined so much to technological investments to reduce the emission as to the global buy of rights of emission that will be realized.

According to a study of the counsel McKinsey, who takes the principal markets as a reference centre Europeans, one of the principal consequences of the extra charges that will have to confront the energy European sector will be probably the increase of the prices of the energy both for the domestic consumers and for the industrialists. The study foresees equally the acceleration of the process of replacement of the coal for the natural gas as principal combustible of the thermal not nuclear head offices, since a plant of natural gas expresses the half of $\mathrm{CO}_{2}$ that a plant of the same potency fed by coal. These forecasts of McKinsey are based that the price of the rights of emission will become stable in winch $25 €$ for unit in 2008. At this price, it will turn out to be more economic to construct gas plants of high efficiency that to continue producing the coal head offices. The above mentioned will be closed and his rights of emission sold on the market, which will provoke the fall of the prices up to the point that will be profitable again to support the coal head offices to satisfy the increasing demand of electricity, demand that will make to raise the prices of the rights again up to the level of $25 €$. According to McKinsey, a third of the coal plants will be replaced with gas between 2005 and 2012, but being supported in functioning two remaining thirds.

Now then, if the Russian Federation and other Eastern bloc end up by taking part on the common market directly well, well across the Joint Application (JA), the price of the rights of emission will go down much underneath $25 €$ and, therefore, the consequences foreseen by McKinsey will remain strongly attenuated. Equally there will turn out to be very limited the extra charges foreseen by the European Commission.

Between the potential benefits of the starting of the market of rights of emission to the renewable energies in 
the EU it is necessary to point out that the European market of rights of emission of hothouse can contribute benefits limited to the development of the renewable energies in the European Union. With rights of emission assigned mostly of free form, slightly clear limits of allocation and excluding the renewable sources, the extra charges that the energy conventional industry will have to confront for his contamination of hothouse will be modest and, therefore, into little they will help to change the current distortions of the energy market to the detriment of the renewable energies.

It is true, in any case, that the light increase of the prices of the energies will help to do more competitive in terms relative to the renewable sources.

It is important, nevertheless, to leave clear good that, against what they affirm some voices, the light increase of costs that will have to confront the brown energies with the starting of the system of commerce of emission in no case will allow to compensate all his external costs.

With a view to accentuating this tendency, it is important to achieve that the States members auction the possible maximum of rights of emission from the first phase and destine the quantities collected to the promotion of the energy efficiency and the renewable energies.

On the other hand, yes there must stand out the interesting opportunities of business that for the promoters and manufacturers of renewable western technologies will have the financing and construction of plants of generation of heat and/or electricity from renewable sources realized under protection of projects of Joint Application (JA) and Mechanism for a Clean Development (MCD) in the States of the East of Europe and in the developing countries, respectively. It will be only possible, nevertheless, if the juridical and economic frame of the countries of reception makes the investment feasible and reduces to the maximum the costs of deal and the regulatory suspense.

If these conditions happen, there is foreseen the achievement of many energy renewable projects.

\section{B. Flexible mechanisms foreseen in the Protocol of Kyoto}

The Protocol of Kyoto foresees the possibility of using three international mechanisms of market - the Commerce of rights of emission (CRE), the Joint Application (JA) and the Mechanism for a Clean Development (MCD) - in order to help to that the States could fulfil in an economically more efficient way the targets of reduction or limitation of emission foreseen in the Protocol. These three mechanisms have been named flexes in the measurement in which they try to introduce a certain flexibility in the routes to reach the targets of reduction of emission.

In contrast to the commerce of rights of emission, the Application Combines (AC) and the Mechanism for a Clean Development (MDL) they are flexible mechanisms based on the project achievement of reduction of emission.
The flexible mechanisms based on projects have, nevertheless, the same economic and environmental logic as the international commerce of rights of emission. On the one hand, these flexible mechanisms allow the States forced by the Protocol of Kyoto to fulfil his targets of reduction or limitation of emission of a more economic form to it to be able to realize a part of the above mentioned reduction of emission in other countries, in which the cost of the same one is lower than the cost that would have to realize it in the territory of the proper State.

On the other hand, and from an environmental point of view, the place where the reduction of the emission takes place has little importance if there are obtained real reductions of the same ones, last target of the flexible mechanisms.

As well as the starting of the common market of rights of emission does not need in strict sense the coming into effect of the Protocol of Kyoto, since the European Board of Commerce of Rights of Emission has a juridical proper and autonomous life, the flexible mechanisms based on projects yes that need the coming into effect of the Protocol to be juridically effective.

\section{Projects of Combined Application (AC)}

Together with the Mechanism for a Clean Development (MCD), the Joint Application (JA) is one of two flexible mechanisms of Kyoto based on projects. By means of the JA, any State that has assumed in the Protocol of Kyoto obligations of reduction or limitation of his emission of greenhouse will be able to acquire and, therefore, to take into account like proper the reductions of emission of hothouse realized in other countries included in the same list. For it, he will have to help in these countries to finance projects that they contribute to the reduction of the emission of hothouse in the same ones.

The projects of Joint Application have, therefore, as active States and recipients States to the same group of countries: the developed western countries and the countries developed of the East Europe in transition to the economy of market. It is foreseen that the JA is a good mechanism of transference of advanced technologies, especially to Russia, where a great potential exists for the investments of JA in the energy sector, which will be translated in an increase of the investments of the companies of the EU.

Although it will not be the most frequent thing, the Combined Application will be able to happen also between two countries of the EU. In fact, only four months ago the first project of JA appeared between Germany and Spain in the field of the biomass, promoted in Archidona (Malaga) for the German company Inergetic and the Town hall of the locality.

The reductions or credits of emission derived from the projects taken refuge in the Joint Application (JA) will be quantified by means of the called Units of Reduction of Emission (URE) that will send the country in which the project is executed. The execution of a project of AC will imply a transference of UREs of a country to other although the entire emission authorized to each of two 
countries will continue being the same. Although any project of JA will have to be passed for two taking part States, the same ones will be able to authorize to legal persons to take part in actions conducive to the generation, transference and acquisition of UREs. This possibility opens the door for the participation of the private sector in the project achievement of JA.

In fact, it is hoped that it should be the private sector the one that principally carries out these projects. The acquisition on part of the Credit states of emission proceeding from the JA will always have to be supplementary to the adoption of the national measurements adapted to fulfil the commitments of reduction of Kyoto. Also, no State will be able to acquire URES if it has not established a national system of estimation of his emission. Mechanism for a Clean Development (MCD)

\section{Mechanism for a Clean Development (MCD)}

Together with the Joint Application (JA), the Mechanism for a Clean Development (MCD) is one of two flexible mechanisms of Kyoto based on projects. By means of the MDL, any State that has assumed in the Protocol of Kyoto obligations of reduction or limitation of his emission of hothouse will be able to acquire and, therefore, to take into account like proper the reductions of emission of hothouse realized in other countries not included in the said list. For it, he will have to help to finance projects in these countries that they contribute to the reduction of the emission of hothouse in the same ones.

The projects of MCD will have, therefore, as active subjects to the developed western countries and as principal fastened recipients to the developing countries. The project execution of MCD will contribute that the developed countries could fulfil in a way as economic as possible a part of his targets of reduction or limitation of emission, impelling, at the same time, the sustainable development in the countries recipients of the projects.

It is foreseen that the MCD is a good mechanism of transference of advanced respectful technologies with the environment to the developing countries.

The reductions or credits of emission derived from the projects taken refuge in the Mechanism for a Clean Development (MCD) will quantify by means of the socalled Certified Reductions of Emission (CRE), which the Executive Meeting of the MCD will send, the organism of the United Nations Convention on the Climatic in charge Change entrusted to supervise the application of the MCD.

The RCE can already obtain regard of projects started from the year 2000 although only they will be able to be used from the year 2008, year in which there begins the first period of commitment of Kyoto.

They will be able to take part in the MCD so much deprived entities as public, although the approval of the projects will always correspond to the States. It is hoped, nevertheless, that it should be the private sector the one that principally impels the projects of MDL.

\section{Funds of Carbon}

The called Funds of Carbon are financial instruments of collective investment in projects of Combined Application (JA) and of Mechanism of Clean Development (MCD). The Fund receives economic contributions of his participants, who can be so much companies deprived as Governments. The Fund invests the resources contributed in projects of JA and of MCD and remunerates the investors, in proportion to his shares, with credits of emission - units of Reduction of Emission (URE) and Certified Reduction of Emission (CRE) obtained in the financed projects.

The participants in these Funds are, so, both Governments and issuing companies of gases of hothouse that need to acquire credits of emission to help to fulfil the duties derived from Kyoto. By means of his participation in the Funds of Carbon, States and companies they can obtain credits AC and MDL with fewer costs of deal and risks of those that they would have if they had to impel directly the projects.

The first Fund of Carbon created in the world, Prototype Carbon Fund, was thrown by the World Bank in 1999. In him there take part six States - Holland, Canada, Sweden, Finland, Norway and Japan - and 17 companies between them, BP, Gaz de France, Electrabel, Deutsche Bank and Mitsubishi - that in whole have contributed 180 million dollars to invest throughout 2004 in at least 30 projects.

Between the chosen projects minihydraulic plants are in Uganda and Costa Rica, a plant of use of the biogas of a dump in Latvia, wind parks in Costa Rica and Colombia, a plant of biomass from rind of rice in Nicaragua and a plant geothermic and different of district heating in Poland.

The World Bank and the International Association of Commerce of Emission threw in July, 2003 the second Fund of Carbon, Community Development Coal Fund, in order to invest exclusively in projects MCD of small scale. Endowed initially with 35 million dollars, in the Fund there take part initially the States of Holland, Canada and Italy, jointly with companies like Basf, Nippon Oil and Endesa.

In parallel, diverse financial institutions and private consultants have started throwing other Funds of Carbon. In Spain, for example, the counsel CO2 Spain, with the collaboration of the broker CO2e.com and Baker and McKenzie develops the throwing of the Spanish Fund of Carbon.

The Spanish Department of Economy has considered to be opportune to study, together with the World Bank, the possibility of creating a Fund of specific carbon for Spain.

\section{CONCLUSIONS}

The present document tries to synthesize and to approach a global vision of the political technological ones and of 
the financial hardware designed and put at the disposal of the Countries signatories of the Protocol of Kyoto that allows them to fulfil in an efficient way with the obligations of reduction and limitation of gas emission of greenhouse effect simultaneously that develop political of diversification and enlargement of markets and programs of transference and technological innovation in developing countries.

The work contributes an of integration vision of the aspects associated with the external economies of the energy sector, the instruments of control of the contamination of the environment and the political ones and instruments developed by the Countries that have assumed commitments quantified of limitation or reduction of emission of greenhouse effect.

The development of new international instruments, of new financial operators and of flexible systems of development of programs of investment who guarantee the sustainable development and the diversification of the investment with specializing operators of management of risk they open new expectations and opportunities of business based on projects of industrial investment.

The design of a system of securing of convertible Credits of Emission from Units of reduction of Emission and Certified Reductions of Emission they open new horizons of diffusion of the renewable energies beyond the promotion of the electricity generated from sources of energies renewable on the domestic market of the electricity (Board 2001/77/CE).

\section{FUNDAMENTAL REFERENCES}

Board 2003/87/CE of the European Parliament and of the Advice of October 13, 2003.

Busquin, Ph.; External Costs. European Commision. European Communities. Belgium, 2003.

CAPRA (1991): " The new ecological paradigm ". Integral magazine. N $^{\circ} 22$. Monographic: " Piece of news Makes aware". Pp. 26-31.

CARMONA, CARRASCO AND FDEZ-REvUELTA (1993): "An approach to interdiscipline of the accounting of the environment ". Spanish magazine of Financing and Accounting. Vol. The XXII N ${ }^{\circ}$ 75. April - July. P. 277-305

Green Book on the Commerce of Rights of Gas Emission of Hothouse effect in the European Union.

Redondo Gil, C. y CaRBajo Nogal, C.; Regulatory strategies of the Renewable Energies in the European Union. The Ist Technical congress on Renewable Energies. Chair of the Renewable Energies of the University of León.

Departament of Economy and Employment of the Meeting of Castile and León. General direction of Energy and Mines.

University of León, November, 2003.

REDONDO GIL, C.; Environmental strategies in the mining and energy sectors. Security, Quality and Environment in the Engineering of Mines: Our Future (2003). Department of Economy. General Direction of Energy Politics and Mine. Official Laboratory Madariaga Polytechnical University of Madrid. Univ. Polytechnical of Catalonia. (Barcelona) November, 2003.
Sixth Program of Community Action on the Subject of Environment; Decision n ${ }^{\circ}$ 1600/2002/CE of the European Parliament and of the Advice.

\section{OTHER REFERENCES}

Bulletin Renewable Energies (Spain) On September 23, 2003.

BUCHANANM J.M. y STUBBLEBINE, W.C.; Externality, Econometrica núm. 24, Nov. 1962, Pp. 37-84.

BurkheAd, J., y Miner, J.; Public Expenditure, Aldine Publishing Company. USA, 1971.

CoAse, R. H.; The Problem of Social Cost. The Journal of Law and Economics, 3. Oct. 1960, Pp. 1-44

Cuervo, A ; Analysis and financial Planning of the Company. Civitas, Madrid, 1994..

Board 196/61/CE; Prevention and control integrated of the contamination.

DoRnBusch, R. ; FISCHER, S. Y Bossons, J.; Macroeconomics and Finance. The MIT Press, Londres, 1987.

Strategy of Saving and Energy Efficiency 2004-2012. Secretary of State of Energy. June, 2003.

Haugen, R. A. Modern Invetment Theory. Prentice Hall International. Englewood Cliffs, N.J., 1990.

Holtenmann, S.E.; Externalities and Public Goods. Economica, Feb. 1972 Pp. 38-78

http://europa.eu.int/comm/energy/intelligent/index

JONES, C.P.; Investments. Analysis and Management. John Wiley and Sons, Nueva York, 1991.

LEVY, H. Y SARNAT, M.; Capital Investment and Financial Decisions, Prentice Hall International. Nueva York, 1990.

Law 24/2001, of December 27 of Fiscal, Administrative measurements and of Social Order, of the General budgets of the Been 2002

Law 54/1997, of November 27 of the Electrical Sector

ManagEnergy website www.managnergy.net

MAULEON, the I.st; Investments and financial risks. Espasa Calpe. Madrid, 1991

Plan of Promotion of the Renewable Energies modified by the Planning of the sectors of the Electricity and Gas. Development of the Networks of Transport 2002-2011. (Approved by the Ministers' Advice 13/09/2002).

Royal decree 2818/1998

Royal decree 841/2002.

Royal decree Law 6/2000 of June 23, of Urgent Measurements of Intensification of the Competition on Markets of Goods and Services.

Board 2003/96/CE of the Advice of October 27, 2003 by that there is restructured the community diet of imposition of the energy products and of the electricity.

Board 96/92/CE of the European Parliament and of the Advice of December 19, 1996 on common norms for the domestic market of the electricity

Proposal of board of the European Parliament and of the Advice on the promotion of the cogeneration on the base of the demand of useful heat on the domestic market of the energy 
Communication of the Commission - Energy for the future: renewable sources of energy - White Book for a strategy and a plan of action community

93/389/CEE: Decision of the Advice, of June 24, 1993, relative to a mechanism of pursuit of the emission of $\mathrm{CO}_{2}$ and of other gases of hothouse effect in the Community.

1999/296/CE: Decision of the Advice, of April 26, 1999, by that the Decision is modified 93/389/CEE relative to a mechanism of pursuit of the emission of $\mathrm{CO}_{2}$ and of other gases of greenhouse effect in the Community

2004/280/CE: Decision of the European Parliament and of the Advice, of February 11, 2004 relative to a mechanism of pursuit of the gas emission of greenhouse effect in the Community and of the application of the Protocol of Kyoto

Board 2003/87/CE of the European Parliament and of the Advice, of October 13, 2003, by that a diet is established for the commerce of rights of gas emission of greenhouse effect in the Community and by that the Board is modified 96/61/CE of the Advice (pertinent Text to effects of the EEE)

Proposal of board of the European Parliament and of the Advice by which there is modified the Board by which a diet is established for the commerce of rights of gas emission of greenhouse effect in the Community with regard to the project mechanisms of the Protocol of Kyoto.

Orientations for the Been members on the application of the criteria of the attached IIIrd of the Board 2003/87/CE by that a diet is established for the commerce of rights of gas emission of greenhouse effect in the Community and by that the Board is modified 96/61/CE of the Advice, and circumstances in which the situation of force majeure remains demonstrated

Board 2001/81/CE of the European Parliament and of the Advice of October 23, 2001 on national roofs of emission of certain atmospheric pollutants

Board 96/61/CE of the Advice of September 24, 1996 relative to the prevention and to the control integrated of the contamination (IPPC).

Decision of the Advice 2002/358/CE, of April 25, 2002, relative to approval, on behalf of the European Community, the Protocol of Kyoto of the Convention Marco de las Naciones Unidas on the Climatic Change and to the joint fulfillment of the commitments contracted according to the same one.

Proposal of Regulation of the European Parliament and of the Advice on certain gases fluorados of hothouse effect.

Communication of the Commission to the Advice and to the European Parliament On Political and measurements of the EU to reduce the gas emission of greenhouse effect: Towards an European Program on the Climatic Change (PECC). 